\title{
Experimental and Computational Methods Pertaining to Surface Tension of Pharmaceuticals
}

\author{
Abolghasem Jouyban ${ }^{1}$ and Anahita Fathi-Azarbayjani ${ }^{2}$ \\ ${ }^{1}$ Drug Applied Research Center and Faculty of Pharmacy, \\ Tabriz University of Medical Sciences, Tabriz, \\ ${ }^{2}$ Faculty of Medicine, Urmia University of Medical Sciences, Urmia,
}

Iran

\section{Introduction}

The molecules of a fluid experiences attractive forces exerted on it by all its neighboring molecules. In the bulk of the liquid, molecules are attracted equally in all directions resulting in a net force of zero. Molecules at or near the surface experience attractive force which tends to pull them to the interior. Surface chemistry deals with thermodynamic and kinetic parameters that take place between two different coexisting phases at equilibrium. Surface tension, $\gamma$ is free energy of the surface at any air/fluid interface defined as force per unit length or energy per unit area. The latter term, also called surface energy, is more useful in thermodynamics and it applies to solids as well as liquid surfaces. The surface free energy of a liquid is measured by its surface tension and the surface free energy of a solid can be revealed by contact angle measurements. The surface tension measurement depends very markedly upon the presence of impurities in the liquid, temperature and pressure changes (Buckton, 1988).

Surface tension is a phenomenon that we see in our everyday life. Human biological fluids, e.g. serum, urine, gastric juice, amniotic liquid, cerebrospinal and alveolar lining liquid contain numerous low-and high-molecular weight surfactants, proteins and lipids that adsorb at liquid interface. The physicochemical processes that take place in these interfaces are extremely important for the vital function of body organs and have a great impact on pharmacodynamic parameters of drug molecules (Kazakov et al., 2000; Trukhin et al., 2001). Drug substances are usually administered as part of a formulation in combination with excipients that have varied and specialized pharmaceutical functions. The design of drug formulation is based on the principles of pharmacokinetic, biopharmaceutic and pharmaceutical technology. The pharmaceutical industry has directed its attention mainly to the quality and processability of active pharmaceutical products which is reflected in various physicochemical parameters. The drug and pharmaceutical materials require extensive characterization and testing of their stability, physico-chemical properties, effectiveness, palatability and ease of administration to ensure drug efficacy. Among the important characteristics are the drug dissolution and solubility in gastrointestinal tract, intestinal absorption, drug distribution and drug- 
plasma protein binding. By applying special surface treatments such as contact angle and surface tension measurements to pharmaceutical compounds, drug distribution, dissolution behavior and release pattern in various body fluids can be improved (Hancock et al., 1997; Ho et al., 2010).

Surface tension can influence the development, prediction and performance of pharmaceutical products and help to solve industrial problems and improve products quality. Due to the importance of this phenomenon in drug formulations, there is a growing need for specific interfacial consideration that can be used routinely to solve pharmaceutical problems and improve product quality and stability. In order to meet challenges and develop new and better performing pharmaceutical products, knowledge of surface tension and its measurements techniques is of utmost importance. Amongst many techniques used for characterizing the surface energies of pharmaceuticals are the surface tension measurements, contact angle and wettability tests (Buckton, 1988; Chamarthy et al., 2009; Puri et al., 2010). The objective of this chapter is to introduce experimental and computational methods of surface tension measurment in the pharmaceutical industry.

\section{Standard methods and instrumentations of surface tension measurement}

Surface tension is a very complicated property of a liquid and it depends upon many variables such as temperature, composition of the solution, measurement time, materials of the apparatus and viscosity of the liquid. When a new surface is being formed, surface active chemicals diffuse to the surface and align. During this process, the surface tension is changing rapidly and continuously. Dynamic surface tension measurements allows track of these changes. When the process reaches equilibrium, static surface tension is obtained by measuring the maximum force at a liquid/gas interface on a sample where the net forces on the line is zero during the test time. Pure fluids and solvents have a single surface tension value and are measured with these devices (Drelich et al. 2002, Thiessen and Man, 1999).

There are a number of commonly available methods for measuring surface tension of liquids. Each has its advantages and limitations. The choice of a method depends on the nature of system to be studied and its stability, the degree of accuracy required, the condition under which its tension is to be measured and possibly on the ability of the instrument to automate the measurements. Realistically the surface tension values of a liquid will vary depending upon the method used (Thiessen and Man, 1999). The following section describes the most used methods for measuring static and dynamic surface and interfacial tension of liquid mixtures as well as semi solids and solids (a summary of the methods is shown in Table 1).

\subsection{Wilhelmy plate method}

The Wilhelmy plate consists of a thin glass, platinum plate or pre-wetted paper, usually on the order of a few centimeters square, attached to an electrobalance via thin metal wire and is used to measure equilibrium interfacial tension at an air-liquid or liquid-liquid interface (Figure 1). The metal plate must be cleaned from organic contaminants or test solutions, therefore the plate is flamed before the experiment to avoid contamination and to help maintain good wetting of the plate by the test liquid. The plate is then immersed and retracted into and out of the test solution contained in a beaker on a mechanical stage. During these cycles the force acting on the plate vs. depth of immersion are recorded. The 
meniscus formed at the solid-liquid interface is characterized by the contact angle. Two contact angles are measured, an advancing contact angle and a receding contact angle and the surface tension is calculated from the resulting force. The wetting force is monitored with time and this method is specially suited to check static surface tension value which in some cases is more than $4 \mathrm{~h}$, hence the measurements are assumed to represent equilibrium. The main drawback of this method is that the surface age (time taken from surface formation till measurement) is not taken into account. When working with viscous liquids it takes time for a viscous material to flow from the dipped portion of the plate. Thus the surface tension will decrease initially till it reaches a pleatue once the excess liquid has flowed from the plate, therefore this method is not suited for highly viscous solutions (Avranas and Taspoulos, 2000; Krishnan et al., 2005; Santos and Castanho, 2004). The static wetting force on the plate is used to calculate the static surface tension $(\gamma)$ using the Wilhelmy equation:

$$
\gamma=\frac{F}{l \cdot \cos \theta}
$$

where $F$ is the difference in wetting force upon immersion and withdrawal in $\mathrm{mN} / \mathrm{m}, l$ is the wetted perimeter of the Wilhelmy plate and $\theta$ is the advancing or receding contact angle between the liquid phase and the plate. The contact angle $\theta$ of most liquids against platinum plate or clean glass is often assumed to be zero. This method does not require other correction factors such as fluid density. This method can be used to measure the contact angle and wetting properties of solid surfaces, where the platinum ring plate is replaced by the test surface (Avranas and Tasopoulos, 2000; Krishnan et al., 2005; Santos and Castanho, 2004; Sipahi, 2001; Tan et al., 2005).

The static contact angle, $\theta$, is an important parameter in many industries including pharmaceutics. Contact angle measurements span every pharmaceutical field, from fluid dynamic to powder and tablet (Muster and Prestidge, 2002), adhesion and spray-drying of various drug delivery systems (Millqvist-Fureby et al., 1999) to the detection of impurities in the solutions of surface active compounds (Al-Maaieh and Aburub, 2007). It is of particular interest in powders, because the formulations are dependent on the contact angle. Contact angle measurements can be performed using various methods including Wilhelmy plate method, capillary rise method, goniometer and sessile drop method (Dingles and Harris, 2005). Among the interfacial tensiometry methods, the Wilhelmy plate method has been extensively developed and used by scientists in the pharmaceutical industry. The equipment used in this method is commercially available at several companies. With this technique it is possible to measure and control interfacial properties in granulation and tabletting, (Dreu et al., 2005) polymeric surfactants, emulsions and foams, protein-phospholipid interaction (Oritz et al., 2003), interfacial tension of topical skin formulations (Vejnovic et al., 2010), bioadhesive forces between mucosal tissue and microsphere drug delivery system (Vasir et al., 2003).

\subsection{Du Noüy ring method}

Du Noüy ring method is a traditional method used to measure static surface or interfacial tension. The measurement simply requires the ring to be wetted by the liquid and then pulled through the interface while measuring the force exerted on the ring (see Figure 1). Wetting properties of the surface or interface have little influence on this measuring technique. As in the case of Wilhelmy plate, the ring, with a diameter of $2-3 \mathrm{~cm}$, is usually 
made up of platinum or iridium is submerged into liquid and then pulled through the liquid-air interface. Maximum pull exerted on the ring by the surface is measured which is directly proportional to the surface tension value at equilibrium (Bodour and Miller-Maier, 1998). The ring is submerged into the solution and then slowly pulled through the liquid-air interface to detach from the interface with a force that is correlated to the surface tension. With this method, it is possible to measure the interfacial tension at both liquid-air and liquid-liquid interfaces. Surface tension can be calculated using the equation below:

$$
\gamma=\frac{F}{p \cos \theta} f
$$

where $p$ is the perimeter of the three-phase contact line, $f$ is the correction factor (because additional volume of liquid is lifted during the detachment of the ring from the interface) between each measurement. The platinum wire ring was rinsed three times with water, later with acetone as was blow dried (Drelich et al., 2002).

One major difference between the Du Noüy ring method and Wilhelmy's plate is the way in which the surface tension measurement is carried out. The ring moves through the interface whereas the plate is static at the interface, therefore there is no disturbance at the interface and this method is the recommended geometry for studying time dependent characteristics. Both ring and plate geometries can be used with the force balance type of tensiometer. A single instrument is normally capable of performing either Wilherlmy plate or du Noüy ring measurements (Thiessen and Man, 1999).

The surface tension measured by du Noüy method has been utilized in pharmaceutical research, for example, in the measurement of emulsion stability (Ishii et al., 1988; Takamura et al., 1984) and development of a dissolution media to simulate the physiological environment of the gastric region (Luner et al., 2001). This method can be used for characterization of pharmaceutical formulations such as plasticizer and polymer coating and surface tension calculation of various surfactant solutions and their CMC values (Palma et al., 2002) at the point of intersection of the interfacial tension value versus surfactant concentration plot (de la Maza, 1998; Korhonen et al., 2004; Zelkó et al., 2002).

\subsection{Maximum bubble pressure method}

The maximum bubble pressure method involves flow of a gas bubble (typically air or nitrogen) at a constant rate and blows them through a capillary with a known diameter which is submerged in the sample liquid. The pressure inside of the gas bubble increases until the bubble becomes hemispherical and its radius corresponds to the radius of the capillary. Beyond this the bubble is unstable and grows explosively until it detaches itself from the capillary and a new bubble is formed. The method is based on the continuous measurement of the applied pressure versus bubble rate formed at the end of the capillary. Figure 1 shows each step of bubble formation and corresponding change of bubble radius. The dynamic surface tension can be directly calculated by Young-LaPlace equation:

$$
\gamma=\frac{\Delta P_{\max } R}{2}
$$

where $\Delta P_{\max }$ is the maximum pressure difference and $R$ is the capillary radius (Drelich et al., 2002; Hallowell and Hirt, 1994; Fainerman et al., 2006). This method is one of the most popular 
techniques to measure the dynamic surface tension of various surfactants around and above their CMC value where adsorption is rapid (Christov et al., 2006). In the maximum bubble pressure method, a single interfacial tension value is drawn from each bubble formed. This device is the only available method capable of measuring surface tension in milliseconds time range. This method is particularly useful in measuring surface tension of highly concentrated surfactant solutions (Mischuk et al., 2000) and molten metals (Drelich et al., 2002).

\subsection{Drop volume/weight method}

Among the conventional methods of surface tension measurement, drop shape techniques have proven to be reliable and easy to handle. This method weighs the mass of the liquid drop or the volume of the drop that falls off a capillary tip of known diameter when pumped very slowly. The weight of the drop falling off the capillary correlates with the interfacial tension and is measured by balancing it against a known gravitational force through the following equation:

$$
W=V \Delta \rho g=2 \pi r f
$$

where $\Delta \rho$ is the difference in the density of the heavy phase and the light phase, $g$ is the gravitational constant $\left(g=9.81652 \mathrm{~m} / \mathrm{s}^{2}\right), r$ is the radius of the capillary tip and $f$ denotes the empirical drop correction factor introduced by Harkins and Brown. The correction factor is required because only a portion of the drop falls from the capillary tip during detachment and this corrects the deviation of the drop volume from its ideal value (Drelich et al., 2002; Gunde et al., 2001). Impurity of active pharmaceutical solutions (Al-Maaieh and Aburub 2007), emulsion stability (Rangsansarid and Fukada, 2007), potency of local anesthetics (Matsuki et al., 1998), stability of biphasic aqueous systems (Mishima et al., 1998) and surface active properties of drugs (Deo et al., 2004) have been evaluated using this technique.

\subsection{Pendant drop method}

Most of surface tension measurement techniques have limitations and only a few are suitable for protein solutions and high viscous solutions such as polymers blends. As discussed earlier, the Wilhelmy plate technique requires the establishment of a zero contact angle of the liquid at the plate which is difficult to guarantee with systems involving protein solutions and polymeric solutions with high viscosity. Du Noüy ring method, the drop volume technique or the maximum bubble method also lack dynamic control (Chen et al., 1999). In general, the equilibrium static methods such as sessile drop, spinning drop or a pendant drop method are most commonly used for measuring surface tension of molten metals and viscous solutions (Arashiro and Demarquette, 1999).

The pendent drop technique is capable of producing highly accurate static as well as dynamic interfacial tensions and contact angle measurements. This method is mostly used for the surface tension measurements of metals, alloys and polymers. In this method geometry of the drop is analyzed optically. The increased accuracy and simplicity of this ground based method allow ultra low surface tension, temperature and time dependence of interfacial tension as well as surface tension measurements at elevated pressures (Chen et al., 1999). 
A typical pendant drop apparatus (see Figure 1) consists of three parts:

1. An experimental compartment, which includes a microsyringe to produce a pendent drop of a solution at the tip of a capillary, to measure the maximum volume of the drop at reservoir conditions (pressure and temperature).

2. A viewing system to visualize the drop; this part consist of an accurate video system and magnification factor for the image in both the $\mathrm{x}$ and $\mathrm{y}$ direction.

3. A data acquisition system to compute the surface tension from the digital image of the pendant drop (via Laplace's equation).

The accuracy of the surface tension measurements is highly dependent on the imaging system. Images of the drop can be captured automatically at certain frequencies over a period of several hours depending on the time duration of the test. These digitized pendant drop images can be stored on the computer to calculate the surface tension values as a function of the length of time (Arashiro and Demarquette, 1999; Gunde et al., 2001; Semmler and Kohler, 1999).

This method involves the determination of the profile of a drop of one liquid suspended in another liquid at mechanical equilibrium. This is done by the balance between gravity and surface forces. The equation of Bashforth and Adams which is based on Laplace's equation relates the drop profile to the interfacial tension. This is the most widely used method to date which is given below:

$$
\gamma=\frac{\Delta \rho g D_{e}^{2}}{H}
$$

where $g$ is gravitational constant, $\Delta \rho$ is the difference in densities between tile drop and its surroundings and $D$ is the equatorial diameter of the drop at the apex and $H$ is the shape factor that contains the properties of the fluid (Arashiro and Demarquette, 1999; Dingle et al., 2005; Hernández-Baltazar and Gracia-Fadrique, 2005).

Dynamic surface tension of biological fluids (Trukhin et al., 2001), surfactants and protein complexes (Krägel et al., 2003) and surface tension of viscous solutions are some of the examples which employ this method to measure surface tension.

\subsection{Sessile drop method}

The sessile drop method is based on the analysis of the profile of the drop placed on a solid substrate (see Figure 1). The solid may be a flat horizontal plate, a tilted plate, a vertical plate, or the walls of a thin tube (capillary). This method for contact angle determination is, in principle, simple, but great care must be taken to make accurate measurements. When the contact angle is small, a sessile drop is difficult to observe, therefore it is recommended that substrates used in sessile drop measurements be poorly wetted by the drop and should have a contact angle greater than 90 degrees. The liquid is contained in a syringe from which a droplet is deposited onto the substrate, and a high resolution camera captures the image. The drop can then be analyzed either by eye (using a protractor) or using image analysis software to calculate contact angle, surface and interfacial tension, wettability and absorption (Allen, 2003; Dingle and Harris, 2005).

The sessile drop technique can be used to measure contact angle between solid, liquid and vapor phases and characterize the solid surface properties by solving Young's equation: 


$$
\cos \theta_{c}=\frac{\gamma_{S L}-\gamma_{S V}}{\gamma_{L V}}
$$

where equilibrium contact angle, $\cos \theta_{c}$ is related to the interfacial energy of the three involved surfaces; solid-liquid, $\gamma_{S L}$, solid-vapor, $\gamma_{S V}$ and liquid-vapor $\gamma_{L V}$. If $\theta$ is less than $90^{\circ}$, the liquid is said to wet the solid. A zero contact angle represents complete wetting. If $\theta$ is greater than $90^{\circ}$ then it is said to be non-wetting (Bachmann et al., 2000; Dingle and Harris, 2005; Muster and Prestidge, 2002).

The most widely employed method for contact angle studies is to measure the angle of a sessile drop resting on a flat solid surface using a goniometer-microscope equipped with an angle-measuring eyepiece or a video camera equipped with a suitable magnifying lens, interfaces with a computer and an image-analysis software to determine the tangent value precisely on the captured image. Contact angles are obtained at intervals over a period of time. The sessile drop method for contact angle determination is, in principle, simple, but great care must be taken to make accurate measurements. The error associated with this instrument varies based on user expertise. This method employs a single point on the contact line to measure the surface tension, therefore it is not a suitable technique in studying rough and heterogenous surfaces. To obtain reproducible and accurate measurements with rough surfaces it is advantageous to use the Wilhelmy plate method. An advantage of of the sessile drop method is that, the large solid surface allows multiple droplet evaluation. Reproducibility of the surface measured contact angle values will reflect the heterogeneity of the surface's energy properties (Allen, 2003; Dingle and Harris, 2005; Drelich et al., 2002; Ho et al., 2010).

Contact angle is one of the most widely used techniques in the surface characterization and wettability of pharmaceuticals formulations. The sessile drop technique is commonly used for estimating contact angle of pharmaceutical powders (Buckton, 1993), drug-carrier adhesion (Podczeck et al., 1996), compaction and granulation (Puri et al., 2010), emulsion stability (Hansen and Fagerheim, 1998), human biological fluids (Noordman et al., 1999) and dynamic wettability properties of contact lens hydrogels (Ketelson et al., 2005).

\subsection{Spinning drop method}

Spinning drop method is based on the profile analysis of rotating liquid drop or thread where a drop of the less dense phase is put into another heavy phase contained in a horizontal tube. The tube is then spun about its longitudinal axis causing the lower density fluid to centrifuge to the center and form an elongated drop (see Figure 1). The diameter of a drop within a heavy phase is measured while the tube is spun at a constant speed. For each speed of rotation the drop attains equilibrium where the shape of the drop is a balance between interfacial tension and the pressure difference between the phases. With this method the interfacial tension can easily be calculated from Vonnegut's Equation:

$$
\gamma=\frac{1}{4} r^{3} \Delta \rho \omega^{2}
$$

where $r$ denotes the radius of the cylindrical drop, $\Delta \rho$ is the density difference between the drop and the surrounding fluid and $\omega$ is the rotational velocity (Drelich et al., 2002; $\mathrm{Hu}$ and Joseph, 1994; Seifert and Wendorff, 1992). 
This technique has many advantages when compared to the other methods. The centrifugal force used for determining the shape of the interface can be changed at will, however pendant drop and the sessile drop use gravity as the deforming force. This technique is ideal for measuring ultralow interfacial tensions down to $10^{-6} \mathrm{mN} / \mathrm{m}$. Time and temperature-dependent surface tension can be studied using this technique (Seifert and Wendorff, 1992).

Design and manufacturing of a spinning drop device are simple in principle and this method is widely used to study the interfacial tensions of many systems, e.g., polymer melts, organic solvents (Jon et al., 1986; Schoolenberg et al., 1998) and surfactants and emulsions (El-Aaseer et al., 1984; Martin and Velankar, 2008).

\subsection{Capillary rise method}

The origin of this method dates to one century ago, however it is still a subject of interest due to the widespread application in the pharmacy and it is considered the standard method for determining the surface tension and wettability of a liquid. This method is capable of very good accuracy in measurement when suitable precautions are taken. But in practice it suffers from the fact that the calibration of the capillary diameter is tedious. This method is based on measuring the penetration time needed for a liquid to rise to a certain height when the end of a capillary is immersed into the solution (see Figure 1). According to the rising speed, the contact angle may be calculated (Ramírez-Flores et al., 2010; Xue et al., 2006).

The Lucas- Washburn elucidated the dynamics of capillary rise by using the Poiseuille equation for capillary penetration of liquids using the pressure difference across the invading liquid meniscus. When the meniscus is ideally 'hemi-cylindrical' concave in shape, the height at which the solution reaches inside the capillary is related to the surface tension. The wicking of a solvent vertically through a powder is described by Washburn equation:

$$
x^{2}=\frac{r \gamma \cos \theta}{2 \eta} t
$$

where $t$ is the time required for solvent to rise $\mathrm{x}$ millimeters above the solvent through the MPs, $\gamma$ and $\eta$ are the surface tension and viscosity of the solvent, $\cos \theta$ is the cosine of the contact angle and $\mathrm{r}$ is the internal radius of the capillary (Norris et al., 1999; Ramírez-Flores et al., 2010; Xue et al., 2006).

The wetting of small particles and porous materials is a very important phenomenon in pharmaceutical technologies for wettability studies of drug powder and drug manufacturing with related processes. There are a number of available methods, however capillary rise method is a routine measurement for contact angle study of powder and porous materials (Ramírez-Flores et al., 2010; Galet et al., 2010; Xue et al., 2006). Contact angle method for powders can be classified into those which require compaction, and those which utilize penetration of liquid through an uncompacted bed. Powder penetration technique can be measured with the capillary rise method. However it has been found that this method tends to overestimate the contact angle value. An alternative method is to measure the contact angle on a compacted powder surface with the use of sessile drop technique. Disadvantage of the sessile drop method is that compaction may 
change the characteristics of the powder surface; also it requires the compact powder to be fully wetted by the test liquid. These problems may cause this method to underestimate the angle value. In such circumstances, Wilhelmy plate method allows calculation of contact angle without the need to pre-saturate the powder (Buckton et al., 1995).

\subsection{Atomic force microscopy}

Many engineered surfaces and pharmaceutical products cannot be melted, dissolved, or fractured; therefore their surface/interfacial tension cannot be determined through any of the conventional techniques. These conventional techniques are applicable to macroscopic solids with flat and homogenous surface and inert substrate, whereas for microscale surfaces with increased surface-to-volume ratio, or sensitive substrates another method needs to be employed. Atomic force microscopy (AFM) is a well-known tool capable of surface characterization at the atomic scale. This technique can be used to produce high resolution images and can offers contact angle studies for macroscopic surfaces and adhesion force measurements for microscopic and submicroscopic surfaces (Cuenot et al., 2004; Drelich et al., 2004). AFM can also provide information on other surface properties such as stiffness, friction, or elasticity (Alonso and Goldmann, 2003). Atomic force microscope works by scanning the samples surface using a fine tip attached to a cantilever in the equipment. The AFM can be operated in the contact (tip touching the sample) and tapping modes (tip oscillating rapidly above the sample). Thus, a topological or force map of the surface can be constructed which allows us to determine the structural information and surface properties such as surface tension (Edwardson and Henderson 2004; Handojo et al., 2009). The force required to pull the tip off the substrate surface is called pull-off or adhesion force $(F)$ which is directly related to the surface tension of the sample (Drelich et al., 2004):

$$
\gamma=\frac{F}{2 c \pi R}
$$

where $R$ is the radius of the particle (probing tip) and $c$ is a constant which depends on the model of the AFM (Drelich et al., 2004).

Atomic force microscopy allows imaging and measurement of biological and biomaterial samples, ligand-receptor interaction, protein adsorption and folding (Alonso and Goldmann, 2003; Edwardson and Henderson, 2004). This device is fast becoming a valuable tool in the pharmaceutical industry and is used in formulation and surface characterization of liposome vesicles (Maeda et al., 2002), microparticle preparation and biomaterials (Méndez-Vilas et al., 2006), surface characterization of parenteral nutrition bags (Realdon et al., 2003), wetting properties of human hair (Dupres et al., 2004) and other applications are discussed elsewhere (Santos and Castanho, 2004).

\subsection{Oscilating jet method}

The oscillating jet method consists of forcing a stream of liquid under constant pressure through an orifice. By adjusting the osciallation frequency, the liquid vibrates to forms a jet having a series of stationary waves which depends chiefly on the characteristics of the orifice, its position, wave number, rate of flow and the surface tension of the liquid (Chang 
and Franses, 1995; Defay and Pétré, 1962; Stückrad et al., 1993; Thomas and Potter, 1975). Surface tension can be calculated using Bohr equation:

$$
\gamma=\frac{2 \times 10^{3} \rho f^{2}\left(1+1.542 b^{2} / r^{2}\right) \psi}{3 r \lambda^{2}+5 \pi^{2} r^{3}}
$$

where $\gamma$ is the surface tension on the wave surface $(\mathrm{mN} / \mathrm{m}), f$ is the flow rate $\left(\mathrm{m}^{3} / \mathrm{sec}\right), \rho$ is the density of solution $(\mathrm{kg} / \mathrm{m} 3), \lambda$ is the wavelength of oscillation $(\mathrm{m}), r$ is the stream radius (m) , $b / r$ is the wave amplitude, and $\Psi$ differs from unity by about 1 part in 1000 (Thomas and Potter, 1975; Zhang and Zao, 1989).

This method can be employed to measure surface tension versus surface age (dynamic surface tension) for surface age varying between 0.1 and 0.001 second of surfactant solutions and surface elastisity (Defay and Hommelen, 1958; Warszynski et al., 1998). Oscillating bubble method is a similar method in which surface is periodically changed and the resulting surface tension variation is measured. Results have shown that surface tension measurements obtained using these methods are similar in value (Lunkenheimer et al., 1990).

\subsection{Other methods of surface tension measurement}

Laser light-scattering method is a non-invasive technique which is able to measure low values of surface tension without perturbing the interfacial thermal equilibrium (Jon et al., 1986; Huang, 1997). This method takes advantage of microscopic interfacial roughness caused by thermal fluctuations of a liquid surface and can be used to measure soft matter systems including microemulsions and bilayer lipid membranes (Cicuta and Hopkinson, 2004).

Langmuir trough methods can be used to study monolayers of surfactants and lipid solutions. In this method lipid solution is applied dropwise at the water surface with a micro liter syringe. This technique allows accurate measurement of surface and interfacial pressure and measurement of dilatational rheology of interfacial film and like Wilhelmy method this technique is independent of contact angle. Langmuir method can be used to measure equilibrium and dynamic surface tension of alveolar surfactant and lipid monolayers (Aveyard et al., 2000; Hills, 1985).

Pulsating bubble surfactometer can be used for studying the dynamic surface tension behavior of surfactants under constant or pulsating area. This method employs a sensitive transducer to determine the pressure difference across the bubble surface. A known area is pulsated sinosoidally resulting in a range of radius from which the surface tension is calculated. This method has been used for the interfacial measurement of soaps, surfactants and protein solutions and lung surfactant drugs (Chang et al., 1996; Coltharp and Franses, 1996).

The inclined plate method involves flowing a thin layer of surfactant solution over an inclined plate method. Surfactant molecules in the bulk adsorb at the interface and surface tension can be obtained from the flow rate of surfactant solution. However, since a Wilhelmy plate is used to measure the surface tension of the flowing surfactant solution, the lag time may introduce some errors during measurement, therefore, proper care is needed to orient the plate parallel to the flowing solution (Chang and Franses, 1995). 


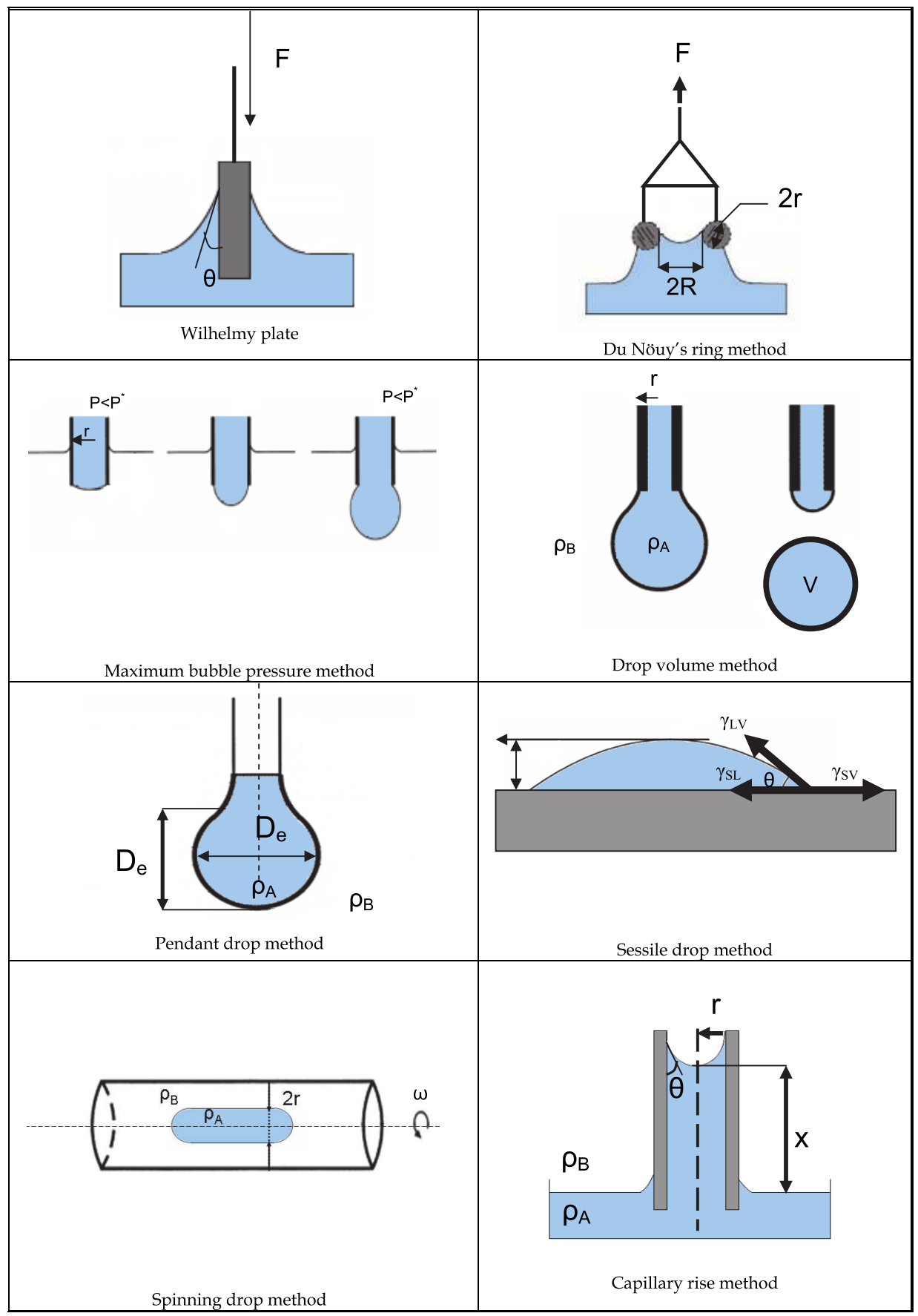

Fig. 1. Schematic illustration of standard methods of surface tension measurement. 


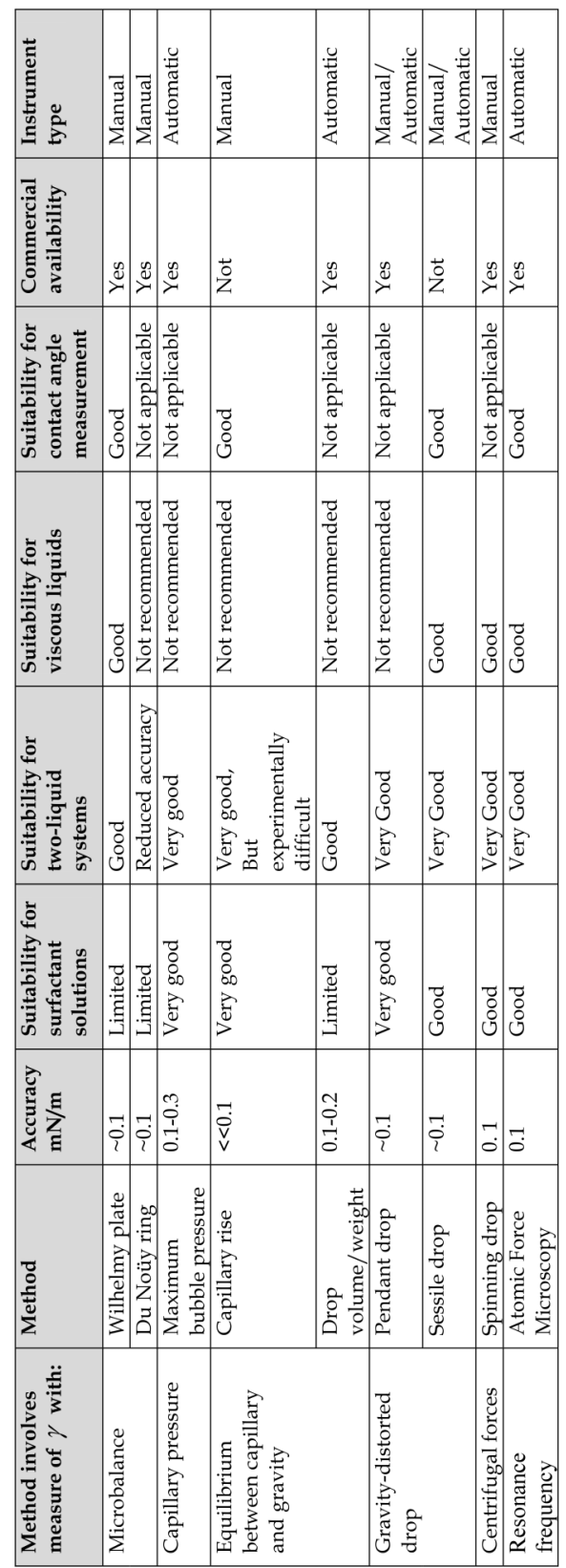

*Drelich et al., 2002

*Thiessen and Man, 1999

*Fainerman et al., 2006

* Xue et al., 2006

Table 1. Accuracy and suitability of classic techniques used in surface tension measurement. 


\section{Computational methods of surface tension measurements}

Modeling of physicochemical properties such as surface tension is needed in the pharmaceutical research. Experimental data on surface tension of liquid mixtures are very scarce in the literature, therefore theoretical methods of their prediction are found to be very useful. Reliable methods of surface tension prediction are useful in design of new materials and will undoubtfuly save laborious experimental measurement time. Surface tension of a liquid mixture is not a simple function of the surface tension of pure components, and is based on the assumption that the composition of the bulk phase is different from the composition of the adjacent vapor-liquid interface. There are various computational techniques in which the surface tension is evaluated through its thermodynamic definition or with the use of empirical equations. Most models require surface tension of the pure components. Models differ in the way in which the molar surface area and the activitycoefficients of the components are calculated (Bezerra et al., 2010; Pandey and Srivastava,2010). Evaluation of the performance of the models is calculated through average absolute deviation, $\mathrm{AAD}(\%)$ for $\mathrm{M}$ data points using equation 11:

$$
A A D(\%)=100\left[\sum_{i=1}^{M} \frac{\left|\left(\gamma_{\exp }-\gamma_{\text {calc }}\right) / \gamma_{\exp }\right|}{M}\right]
$$

With this, the reported experimental values of surface tension obtained using experimental methods are compared with predicted surface tension values from the proposed model.

The following topics present some literature models proposed for correlation and prediction of surface tension of liquid mixtures and solid surfaces.

\subsection{Surface thermodynamic theory}

The thermodynamic methods are based on the fact that surface layer between the bulk liquid and vapor phases has its own composition which affect the surface tension of the mixture. The number of the surface active molecules that reside on the surface can be calculated by the Gibbs adsorption equation:

$$
\Gamma=-\frac{1}{R T} \frac{D \gamma}{d \ln c}
$$

where $\Gamma$ is the surface excess or surface concentration in moles per unit area of surface, $c$ is the concentration of the substance in the bulk solution, $\gamma$ is the surface tension, differential $\mathrm{d} r / \mathrm{d} c$ show the change in surface tension with change in concentration, $R$ is the gas constant and $T$ is the temperature (Ramírez-Verduzco et al., 2006). Butler developed an application of Gibbs energy based on the assumption that the surface layer can be treated thermodynamically as a separate phase from the bulk phase. Some important thermodynamic-based equations were developed from the Butler equation and have been studied for their ability to correlate the surface tension of non-ideal mixtures. Sprow and Prausnitz developed an equation to correlate the surface tension of binary and multicomponent liquid mixtures by employing UNIFAC to calculate the activity coefficients of the individual components at the interface and in the bulk of the liquid. The predictive method of Sprow and Prausnitz was applied to 4 systems including binary and ternary 
systems of water, ethyl butyrate/propionate and methanol at a constant temperature with an AAD value of less than 3.0 \% (Kijevcanin et al., 2004; Rafati and Ghasemian, 2008).

Shereshefsky (1967) presented a model for the surface tension of binary solutions which is able to compute the excess properties and free energy changes in the surface region. This model was applied to 100 aqueous and 200 non-aqueous binary solutions at constant temperature. The agreement between the calculated and the experimental data is found to be very good with AAD of $\sim 1.8 \%$ for aqueous and $\sim 0.6 \%$ for non-aqueous systems (Tahery et al., 2005). Guggenheim (1945) derived an equation for the surface tension as a function of heat for ideal solutions. Hildebrand and Scott extended this model for mixtures with dissimilar molecules. Eberhart (1966) employed a statistical thermodynamic approach and developed a one-parameter equation for binary liquid mixtures with good accuracy (Tahery et al., 2005).

A two-parameter equation was developed based on Wilson theory (Fu et al., 1986). This model was trained for a large number of systems and was able to correlate the data of 251 binary systems with an ADD of $0.5 \%$. Li and co-workers extended that model and used the UNIFAC group contribution method to propose another two-parameter model to calculate the surface tension of binary mixtures (Kijevcanin et al., 2004; Li et al., 1990; Tahery et al., 2005).

$\mathrm{Li}$ and $\mathrm{Lu}$ have developed a predictive model for the surface tension of real mixtures on the basis of Davis theory and tested it against molecular dynamics simulation of the surface tension of the Lennard-Jones fluid. The proposed method was found to be suitable for obtaining surface tension values (Davis, 1975; Li and Lu, 2001).

The gradient theory of fluid interfaces is applied to compute the surface tension of various binary and ternary mixtures made up of gas (carbon dioxide, nitrogen or methane) and hydrocarbons. This model employs the Helmholtz energy density of the bulk homogeneous fluid and the influence parameters of the interfacial inhomogeneous fluid to correlate the surface tension of various pure fluids, binary mixtures and binary and ternary mixtures of gas and liquid hydrocarbons with good results. This method is predictive and is able to estimate surface tension values of gas mixtures with satisfactory results (Lin et al., 2007; Miqueu, 2004).

\subsection{Empirical and correlative theories}

MacLeod proposed an empirical method based on the temperature-independent constant $K$, between density $\rho$, and surface tension $\gamma$ :

$$
\gamma^{1 / 4}=K . \rho
$$

Sugden slightly modified MacLeod's original expression to give a constant which he called the parachor (Sugden, 1924). Escobeo and Mansoori generated a model based on statistical mechanics for the prediction of surface tension of pure solvent using the equation of state. This model is shown to represent the experimental surface tension data of 94 pure solvent within 1.1 AAD\% across all temperature ranges (Escobedo and Mansoori, 1996). Later they extended the same conformal solution theory to the case of mixtures of organic liquids. This equation was applied to 55 binary mixtures and the AAD was $0.5 \%$ (Escobedo and Mansoori, 1998). However these equations are complicated and require critical temperature, critical pressure as well as critical compressibility and acentric factor. Therefore this model requires complex computational procedures which may not be suitable in pharmaceutical research. 
There are a few models where the surface tension of the pure liquid is not required. Panday and co workers have extended Brick-Bird corresponding-state model, Goldsack-Sarvas volume fraction statistics and Sanchez method to multicomponent systems. These approaches require the values of thermal expansivity, isothermal compressibility and critical constants of pure components (Pandey et al., 2008).

Redlich-Kister equation expresses the excess energy thermodynamic properties which consist of a function of the mole fraction of each component and an interaction parameter (Redlich and Kister, 1948). An extension of this model was proposed which is able to correlate surface tension with the composition of the conjugate liquid (Fleming and Vinatieri, 1979).

Studies concerning temperature effect on the surface tension of aqueous and non-aqueous solutions are limited. Some of the models require many experimental parameters leading to low precision and accuracy in surface tension prediction. The Jouyban-Acree model was proposed based on the extension of the Redlich-Kister model as:

$$
\ln \gamma_{m, T}=f_{1} \ln \gamma_{1, T}+f_{2} \ln \gamma_{2, T}+\frac{f_{1} f_{2}}{T} \sum_{i=0}^{2} K_{i}\left(f_{1}-f_{2}\right)^{i}
$$

where $\gamma_{m, T}, \gamma_{1, T}, \gamma_{2, T}$ are the surface tension of the mixture and solvents 1 and 2, respectively and $f_{1}$ and $f_{2}$ are the volume fractions of the solvents and $K_{i}$ are the model constant calculated using a no intercept least square method. This model is able to correlate surface tension of binary and ternary mixtures at various temperatures with AAD of 4.1 and $1.4 \%$ respectively (Jouyban et al., 2004a; 2004b). This equation can be extended to correlate different physicochemical properties of solvent mixtures; including acid dissociation constant, dielectric constant, and drug solubility in water-cosolvent mixtures (Jouyban et al., 1999; 2002; 2004a).

Neural network (NN) modeling in quantitative structure-property relationship (QSPR) studies allows prediction of various physicochemical properties from the molecular structure. Reliable methods for prediction of basic physicochemical properties would save time consuming experimental studies. Kauffman and Jurs reported a predictive NN model for surface tension of 213 common organic solvents using 8 descriptors. The root mean square error of the test sets were $2.89 \mathrm{mN} / \mathrm{m}$ (Taskinen and Yliruusi, 2003; Kauffman and Jurs, 2001).

\subsection{Surface tension of immiscible fluids and solids}

Surface tension calculation of immiscible fluids is possible by introducing repulsion between the neighboring particles of different fluids which has been employed in the macro-scale particle method. However equation of state is also possible for this type of measurement (Zhou et al., 2008).

Determination of the surface tension of solids is crucial in pharmaceutical powders and tableting. Amongst the various approaches to estimate the contact angle of solids is the Young equation (see equation 6). This method requires an ideal, flat and homogenous surface, whereas real measurements are carried out on rough and heterogeneous surfaces, on which the typical contact angle measured is an advancing contact angle which is larger than Young's equilibrium contact angle. The surface tension of a solid cannot be easily estimated from the Young's equation because of the two unknown parameters $\gamma_{S V}, \gamma_{S L}$. In order to calculate these quantities, equation of state (EQS) was proposed (Li and Neumann, 
1990). However many researchers have criticized this equation for its thermodynamic analysis (Johnson and Dettre, 1989; Lee, 1993). Another approach is the geometrical methods for measuring surface tension of solids including Owen Wendt and van Oss theory. These methods decompose the surface tension into different components (Owens and Wendt, 1969; van Oss et al., 1986). Ahadian and colleagues compared the surface tension of 41 artificial solid surfaces as predicted by the equation of state and compared it to the values obtained by van Oss theory and Owen Wendt equation. Results indicate that equation of state was capable of good predictability, whereas the geometric methods are limited to higher range surface tension value of solid surfaces (Ahadian et al.,2007).

\section{Conclusion}

Measurements of surface rheological characteristics are of great importance for the pharmaceutical industry. Many of pharmaceutical processes depend on the cohesive and adhesive interactions between the materials used during the preparation of the product. Understanding and determination of surface free energies of both liquid and solid surfaces plays a key role in characterization of materials during their development, formulation and manufacturing of pharmaceutical applications. The chemical activity, adsorption, dissolution, and bioavailability of a drug may depend on the surface of the molecule.

There are several experimental approaches that one can employ to evaluate interfacial tension and large differences can exist among measurement methods. While one method may be proven useful for a number of applications, there are several restrictions that detract from its applicability in a specific system. The choice of the method depends on the nature of the interface, the rheology of the liquid(s), the range of temperature and pressure, ease of analysis, accuracy, precision, surface age, cost and convenience of the probing instrument. Most equilibrium methods may be used to measure dynamic tension, and there are certain methods by which one can measure solely dynamic tension. Most methods involve measurement of forces, interface shapes, pressure differences, or flow rates. Commonly used methods for measuring interfacial tension of various solutions as well as solid systems are mentioned in this chapter.

To facilitate an in-depth process understanding, a combination of experimental and computational design may be integrated in interfacial tension of compounds. Providing a simple method of correlating and predicting the interfacial properties of materials would be of great interest for pharmaceutical technology. There are various computational techniques in which the surface tension is evaluated through its thermodynamic definition or empirical equations. These methods require input data and several adjustable parameters obtained from multicomponent system and the pure component. Some of these equations on a thermodynamic basis are the two-parameter model for liquid mixtures. With these methods calculation of the free-energy between the two systems is a challenge to be accurately determined and these methods are difficult to implement at relatively high temperature due to stability problems. Empirical equations may be used to correlate and predict surface tension using one or two parameters. Some of these models may have limited range of applicability and may require a lot of experimental data. For practical use it is very important that the surface tension of multicomponent system can be predicted from the composition of the conjugate phases and some predictable physical parameters without any adjustable parameters. 
In essence, an attempt has been made in this chapter to review and examine the performance of computational and experimental techniques in which surface tension are evaluated.

\section{Acknowledgment}

This work is dedicated to the spirit of Professor Fathollah Fathi-Azarbayjani, for believing that great things are born from tiny sparks of inspiration.

\section{References}

Ahadian, S.; Moradian, S.; Sharif, F.; Amani Tehran, M. \& Mohseni, M. (2007). Application of artificial neural network (ANN) in order to predict the surface free energy of powders using the capillary rise method. Colloids and Surfaces A: Physicochemical and Engineering Aspects, Vol. 302, pp. 280-285.

Al-Maaieh, A. \& Aburub, A. (2007). Surface activity of a non-micelle forming compound containing a surface-active impurity. International Journal of Pharmaceutics, Vol. 334, pp. $125-128$.

Allen, J.S. (2003). An analytical solution for determination of small contact angles from sessile drops of arbitrary size. Journal of Colloid and Interface Science, Vol. 261, pp. 481-489.

Alonso, J.L. \& Goldmann, W.H. (2003). Feeling the forces: atomic force microscopy in cell biology. Life Sciences, Vol. 72, pp. 2553-2560.

Arashiro, E.Y. \& Demarquette, N.R. (1999). Use of the pendant drop method to measure interfacial tension between molten polymers. Materials Research, Vol. 2, pp. 23-32.

Aveyard, R.; Clint, J.H.; Nees, D. \& Quirke, N. (2000). Structure and collapse of particle monolayers under lateral pressure at the octane/aqueous surfactant solution interface. Langmuir, Vol. 16, pp. 8820-8828.

Avranas, A. \& Tasopoulos, V. (2000). Aqueous solutions of sodium deoxycholate and hydroxypropylmethylcellulose: dynamic surface tension measurements. Journal of Colloid and Interface Science, Vol. 221, pp. 223-229.

Bachmann, J.; Ellies, A. \& Hartge, K.H. (2000). Development and application of a new sessile drop contact angle method to assess soil water repellency. Journal of Hydrology, Vol. 231-232, pp. 66-75.

Bezerra, E.S.; Santos, J.M.T. \& Paredes, M.L.L. (2010). A new predictive model for liquid/air surface tension of mixtures: Hydrocarbon mixtures. Fluid Phase Equilibria, Vol. 288, pp. 55-62.

Bodour, A.A.; \& Miller-Maier, R.M. (1998). Application of a modified drop-collapse technique for surfactant quantitation and screening of biosurfactant-producing microorganisms. Journal of Microbiological Methods, Vol. 32, pp. 273-280.

Buckton, G. (1988). The assessment, and pharmaceutical importance, of the solid/liquid and the solid/vapour interface: A review with respect to powders. International Journal of Pharmaceutics, Vol. 44, pp. 1-8.

Buckton, G. (1993). Assessment of the wettability of pharmaceutical powders. Journal of Adhesion Science and Technology, Vol. 7, pp. 205-219.

Buckton, G.; Darcy, P. \& McCarthy, D. (1995). The extent of errors associated with contact angles, 3 . The influence of surface roughness effects on angles measured using a 
Wilhelmy plate technique for powders. Colloids and Surfaces A: Physicochemical and Engineering Aspects, Vol. 95, pp. 27-35.

Chamarthy, S.P.; Pinal, R. \& Carvajal, M.T. (2009). Elucidating raw material variability importance of surface properties and functionalities in pharmaceutical powders. AAPS PharmSciTech, Vol. 10, pp. 780-788.

Chang, C.-H.; Coltharp, K.A.; Park, S.Y. \& Franses, E.I. (1996). Surface tension measurements with the pulsating bubble method. Colloids and Surfaces A: Physicochemical and Engineering Aspects, Vol. 114, pp. 185197.

Chang, C.-H. \& Franses, E.I. (1995). Adsorption dynamics of surfactants at the air/water interface: a critical review of mathematical models, data, and mechanisms. Colloids and Surfaces A: Physicochemical and Engineering Aspects, Vol. 100, pp. 1-45.

Chen, P.; Policova, Z.; Pace-Asciak, C.R. \& Neumann, A.W. (1999). Study of molecular interactions between lipids and proteins using dynamic surface tension measurements: A review. Colloids and Surfaces B: Biointerfaces, Vol.15, pp. 313-324.

Christov, N.C.; Danov, K.D.; Kralchevsky, P.A.; Ananthapadmanabhan, K.P. \& Lips, A. (2006). Maximum bubble pressure method: Universal surface age and transport mechanisms in surfactant solutions. Langmuir, Vol. 22, pp. 7528-7542.

Cicuta, P. \& Hipkinson, I. (2004). Recent developments of surface light scattering as a tool for optical-rheology of polymers monolayers. Colloids and Surfaces A: Physicochemical Engineering Aspects, Vol. 233, pp. 97-107.

Coltharp, K.A. \& Franses, E.I. (1996). Equilibrium and dynamic surface tension behavior of aqueous soaps: Sodium octanoate and sodium dodecanoate (sodium laurate). Colloids and Surfaces Physicochemical and Engineering Aspects, Vol. 108, pp. 225242

Cuenot, S.; Fétigny, C.; Demoustier-Champagne, S. \& Nysten, B. (2004). Surface tension effect on the mechanical properties of nanomaterials measured by atomic force microscopy. Physical Review B, Vol. 69, pp. 1-5.

Currie, P.K. \& van Nieuwkoop, J. (1982). Buoyancy effects in the spinning-drop interfacial tensiometer. Journal of Colloid Interface Science, Vol. 87, pp. 301-316.

Davis, H.T. (1975). Statistical mechanics of interfacial properties of polyatomic fluids. 1. Surface tension. Journal of Chemical Physics, Vol. 62, pp. 3412-3415.

de la Maza, A.; Coderch, L.; Gonzalez, P. \& Parra, J.L. (1998). Subsolubilizing alterations caused by alkyl glucosides in phosphatidylcholine liposomes. Journal of Controlled Release, Vol. 52, pp. 159-168.

Defay, R. \& Hommelen, J.R. (1958). I. Measurement of dynamic surface tensions of aqueous solutions by the oscillating jet method. Journal of Colloid Science, Vol.13, pp. 553-564.

Defay, R. \& Pétré, G. (1962). Correcting surface tension data obtained by the oscillating jet method. Journal of Colloid Science, Vol. 17, pp. 565-569.

Deo, N.; Somasundaran, T. \& Somasundaran, P. (2004). Solution properties of amitriptyline and its partitioning into lipid bilayers. Colloids and Surfaces B: Biointerfaces, Vol. 34, pp. 155-159.

Dingle, N.M. \& Harris, M.T. (2005). A robust algorithm for the simultaneous parameter estimationof interfacial tension and contact angle from sessile drop profiles. Journal of Colloid and Interface Science, Vol. 286, pp. 670-680.

Drelich, J.; Fang, C. \& White, C.L. (2002). Measurment of interfacial tension in fluid-fluid systems, in: Encyclopedia of Surface and Colloid Science, Hubbard AT, pp. 3152-3166, Marcel Dekker, ISBN: 9780824707965, New York. 
Dreu, R.; Šircab, J.; Pintye-Hodi, K.; Burjan, T.; Planinšek, O. \& Srčič, S. (2005). Physicochemical properties of granulating liquids and their influence on microcrystalline cellulose pellets obtained by extrusion-spheronisation technology. International Journal of Pharmaceutics, Vol. 291, pp. 99-111.

Dupres, V.; Camesano, T.; Langevin, D.; Checco, A. \& Guenoun, P. (2004). Atomic force microscopy imaging of hair: Correlations between surface potential and wetting at the nanometer scale. Journal of Colloid and Interface Science, Vol. 269, pp. 329-335.

Eberhart, J.G. (1966). Surface tension of binary liquid mixtures. Journal of Physical Chemistry, Vol. 70, pp. 1183-1186.

Edwardson, J.M. \& Henderson, R.M. (2004). Atomic force microscopy and drug discovery. Drug Discovery Today, Vol. 9, pp. 64-71.

El-Aasser, M.S.; Lack, C.D.; Choi, Y.T.; Min, T.I.; Vanderhoff, J.W. \& Fowkes, F.M. (1984). Interfacial aspects of miniemulsions and miniemulsion polymers. Colloids and Surfaces, Vol. 12, pp. 79-97.

Escobedo, J. \& Mansoori, G.A. (1996). Surface tension prediction for pure fluids, AIChE Journal, Vol. 42, pp. 1425-1433.

Escobedo, J. \& Mansoori, G.A. (1998). Surface tension prediction for liquid mixtures. AIChE Journal, Vol. 44, pp. 2324-2332.

Fainerman, V.B.; Mys, V.D.; Makievski, A.V. \& Miller, R. (2006). Application of the maximum bubble pressure technique for dynamic surface tension studies of surfactant solutions using the Sugden two-capillary method. Journal of Colloid and Interface Science, Vol. 304, pp. 222-225.

Fleming, P.D. \& Vinatieri, J.E. (1979). Quantitative interpretation of phase volume behaviour of multicomponent systems near critical points. AIChE Journal, Vol. 25, pp. 493-502.

Fu, J.; Li, B. \& Wang, Z. (1986). Estimation of fluid-fluid interfacial tension of multicomponent mixtures. Chemical Engineering Science, Vol. 41, pp. 2673-2679.

Galet, L.; Patry, S. \& Dodds, J. (2010). Determination of the wettability of powders by the Washburn capillary rise method with bed preparation by a centrifugal packing technique. Journal of Colloid and Interface Science, Vol. 346, pp. 470-475.

Guggenheim, E.A. (1945). The principle of corresponding states. Journal of Chemical Physics, Vol. 13, pp. 253-261.

Gunde, R;. Kumar, A.; Lehnert-Batar, S.; Mäder, R. \& Windhab E.J., (2001). Measurement of the surface and interfacial tension from maximum volume of a pendant drop. Journal of Colloid and Interface Science, Vol. 244, pp. 113-122.

Hallowell, C.P. \& Hirt, D.E. (1994). Unusual characteristics of the maximum bubble pressure method using a Teflon capillary. Journal of Colloid and Interface Science, Vol. 168, pp. 281-288.

Hancock, B.C.; York, P. \& Rowe, R.C. (1997). The use of solubility parameters in pharmaceutical dosage form design. International Journal of Pharmaceutics, Vol. 148, pp. 1- 21.

Handojo, A.; Zhai, Y.; Frankel, G. \& Pascall, M.A. (2009). Measurement of adhesion strengths between various milk products on glass surfaces using contact angle measurement and atomic force microscopy. Journal of Food Engineering, Vol. 92, pp. 305-311.

Hernández-Baltazar, E. \& Gracia-Fadrique, J. (2005). Elliptic solution to the Young-Laplace differential equation. Journal of Colloid and Interface Science, Vol. 287, pp. 213-216. 
Hills, B. (1985). Alveolar liquid lining: Langmuir method used to measure surface tension in bovine and canine lung extracts. Journal of Physiology, Vol. 359, pp. 65-79.

Ho, R.; Hinder, J.; Watts, J.F.; Dilworth, S.E.; Williams, D.R. \& Heng, J.Y.Y. (2010). Determination of surface heterogeneity of d-mannitol by sessile drop contact angle and finite concentration inverse gas chromatography. International Journal of Pharmaceutics, Vol. 387, pp. 79-86.

Hu, H.H. \& Joseph, D.D. (1994). Evaluation of a liquid drop in a spinning drop tensiometer. Journal of Colloid and Interface Science, Vol. 162, pp. 331-339.

Huang, Y.-X. (1997). Laser light scattering studies on thermodynamics of C8-lecithin and monovalent salt solutions. Journal of Chemical Physics, Vol. 107, pp. 9141-9145.

Ishii, F.; Takamura, A. \& Ogata, H. (1988). Compatibility of intravenous fat emulsions with prodrug amino acids. Journal of Pharmarmacy Pharmacology, Vol. 40, pp. 89-92.

Johnson, R.E. \& Dettre, R.H. (1989). An evaluation of Neumann's "surface equation of state". Langmuir, Vol. 5, pp. 293-295.

Jon, D.I.; Rosano, H.L. \& Cummins, H.Z. (1986). Toluene/water/1-propanol interfacial tension measurements by means of pendant drop, spinning drop, and laser lightscattering methods. Journal of Colloid and Interface Science, Vol. 114, pp. 330-341.

Jouyban, A.; Chan, H.K.; Clark, B.J. \& Acree, W.E. (2002). Mathematical representation of apparent dissociation constants in aqueous-organic solvent mixtures. International Journal of Pharmaceutics, Vol. 246, pp. 135-142.

Jouyban, A.; Fathi Azarbayjani, A.; Barzegar-Jalali, M. \& Acree, W.E. (2004a). Correlation of surface tension of mixed solvents with solvent composition. Pharmazie, Vol. 59, pp. 937-941.

Jouyban, A.; Fathi-Azarbayjani, A. \& Acree, W.E. (2004b). Surface tension calculation of mixed solvents with respect to solvent composition and temperature by using Jouyban-Acree model. Chemical and Pharmaceutical Bulletin, Vol. 52, pp. 1219-1222.

Jouyban, A.; Soltanpour, Sh. \& Chan, H.K. (2004). A simple relationship between dielectric constant of mixed solvents with solvent composition and temperature. International Journal of Pharmaceutics, Vol. 269, pp. 353-360.

Jouyban, A.; Valaee, L.; Barzegar-Jalali, M.; Clark, B.J. \& Acree, W.E. (1999). Comparison of various cosolvency models for calculating solute solubility in water-cosolvent mixtures. International Journal of Pharmaceutics, Vol. 177, pp. 93-101.

Kauffman, G.W. \& Jurs, P.C. (2001). Prediction of surface tension, viscosity, and thermal conductivity for common organic solvents using quantitative structure-property relationships. Journal of Chemical Information and Computer Science, Vol. 41, pp. 408418.

Kazakov, V.N.; Vozianov, A.F.; Sinyachenko, O.V.; Trukhin, D.V.; Kovalchuk, V.I. \& Pison, U. (2000). Studies on the application of dynamic surface tensiometry of serum and cerebrospinal liquid for diagnostics and monitoring of treatment in patients who have rheumatic, neurological or oncological diseases. Advances in Colloid and Interface Science, Vol. 86, pp.1-38.

Ketelson, H.A.; Meadows, D.L. \& Stone, R.P. (2005). Dynamic wettability properties of a soft contact lens hydrogel. Colloids and Surfaces B: Biointerfaces, Vol. 40, pp. 1-9.

Kijevcanin, M.Lj.; Ribeiro, I.S.A.; Ferreira, A.G.M. \& Fonseca, I.M.A. (2004). Water + esters + methanol: Experimental data, correlation and prediction of surface and interfacial 
tensions at $303.15 \mathrm{~K}$ and atmospheric pressure. Fluid Phase Equilibria, Vol. 218, pp. 141-148.

Krägel, J.; O’Neill, M.; Makievski, A.V.; Michel, M.; Leser, M.E. \& Miller, R. (2003). Dynamics of mixed protein-/surfactant layers adsorbed at the water/air and water/oil interface. Colloids and Surfaces B: Biointerfaces, Vol. 31 pp. 107-114.

Krishnan, A.; Liu, Y.-H.; Cha, P.; Woodward, R.; Allara, D. \& Vogler, E.A. (2005). An evaluation of methods for contact angle measurement. Colloids and Surfaces B: Biointerfaces, Vol. 43, pp. 95-98.

Korhonen, M.; Hirvonen, J.; Peltonen, L.; Antikainen, O.; Yrjänäinen, L. \& Yliruusi, J. (2004). Formation and characterization of three-component-sorbitan monoester surfactant, oil and water-creams. International Journal of Pharmaceutics, Vol. 269, pp. 227-239.

Lee, L.-H. (1993). Scope and limitations of the equation of state approach for interfacial tensions. Langmuir, Vol. 9, pp. 1898-1905

Li, Z.B. \& Lu, B.C.Y. (2001). On the prediction of surface tension for multicomponent mixtures. Canadian Journal of Chemical Engineering, Vol. 79, pp. 402-411.

Li, D. \& Neumann, A.W. (1990). A reformulation of the equation of state for interfacial tensions. Journal of Colloid Interface Science, Vol. 137, pp.304-307.

Li, Z.B.; Shen, S.Q.; Shi, M.R. \& Shi, J. (1990). Prediction of the surface tension of binary and multicomponent liquid mixtures by the unifac group contribution method. Thermochimica Acta, Vol. 169, pp. 231-238.

Lin, H.; Duan, Y.-Y. \& Min, Q. (2007). Gradient theory modeling of surface tension for pure fluids and binary mixtures. Fluid Phase Equilibria, Vol. 254, pp. 75-90.

Luner, P.E. \& Van Der Kamp, D. (2001). Wetting characteristics of media emulating gastric fluids. International Journal of Pharmaceutics, Vol. 212, pp. 81-91.

Lunkenheimer, K.; Serrien, G. \& Joos, P. (1990). The adsorption kinetics of octanol at the air/solution interface measured with the oscillating bubble and oscillating jet methods. Journal of Colloid and Interface Science, Vol. 134, pp. 407-411.

Maeda, N.; Senden, T.J. \& di Meglio, J.-M. (2002). Micromanipulation of phospholipid bilayers by atomic force microscopy. Biochimica et Biophysica Acta, Vol. 1564, pp. 165- 172.

Martin, J.D. \& Velankar, S.S. (2008). Unusual behavior of PEG/PPG/Pluronic interfaces studied by a spinning drop tensiometer. Journal of Colloid and Interface Science, Vol. 322, pp. 669-674.

Matsuki, H.; Shimada, K.; Kaneshina, S.; Kamaya, H. \& Ueda, I. (1998). Difference in surface activities between uncharged and charged local anesthetics: Correlation with their anesthetic potencies. Colloids and Surfaces B: Biointerfaces, Vol. 11, pp. 287-295.

Méndez-Vilas, A.; Donoso, M.G.; Gonz’alez-Carrasco, J.L. \& González-Martín, M.L. (2006). Looking at the micro-topography of polished and blasted Ti-based biomaterials using atomic force microscopy and contact angle goniometry. Colloids and Surfaces B: Biointerfaces, Vol. 52, pp. 157-166.

Millqvist-Fureby, A.; Malmsten, M. \& Bergenståhl, B. (1999). Spray-drying of trypsinsurface characterisation and activity preservation. International Journal of Pharmaceutics, Vol. 188, pp. 243-253.

Miqueu, C.; Mendiboure, B. ; Graciaa, C. \& Lachaise, J. (2004). Modelling of the surface tension of binary and ternary mixtures with the gradient theory of fluid interfaces. Fluid Phase Equilibria, Vol. 218, pp. 189-203. 
Mishchuk, N.A. Fainerman, V.B. Kovalchuk, V.I.R. Miller, R. Dukhin, S.S. (2000). Studies of concentrated surfactant solutions using the maximum bubble pressure method. Colloids and Surfaces A: Colloids and Surfaces A: Physicochemical and Engineering Aspects, Vol. 175, pp. 207-216.

Mishima, K.; Matsuyama, K.; Ezawa, M.; Taruta, Y.; Takarabe, S. \& Nagatani, M. (1998). Interfacial tension of aqueous two-phase systems containing poly (ethylene glycol) and dipotassium hydrogenphosphate. Journal of Chromatography B, Vol. 711, pp. 313-318.

Muster, T.H. \& Prestidge, C.A. (2002). Application of time-dependent sessile drop contact angles on compacts to characterise the surface energetics of sulfathiazole crystals. International Journal of Pharmaceutics, Vol. 234, pp. 43-54.

Noordmans, J.; Wormeester, H. \& Busscher, H.J. (1999). Simultaneous monitoring of protein adsorption at the solid-liquid interface from sessile solution droplets by ellipsometry and axisymmetric drop shape analysis by profile. Colloids and Surfaces B: Biointerfaces, Vol. 15, pp. 227-233.

Norris, D.A.; Puri, N.; Labib, M.E. \& Sinko, P.J. (1999). Determining the absolute surface hydrophobicity of microparticulates using thin layer wicking. Journal of Controlled Release, Vol. 59, pp. 173-185.

Ortiz, S.E.M.; Sánchez, C.C.; Rodríguez Niño, M.R.; Añon, M.C. \& Rodríguez Patino, J.M. (2003). Structural characterization and surface activity of spread and adsorbed soy globulin films at equilibrium. Colloids and Surfaces B: Biointerfaces, Vol. 32, pp. 57-67.

Owens, D.K. \& Wendt, R.C. (1969). Estimation of the surface free energy of polymers. Journal of Applied Polymer Science, Vol. 13, pp. 1741-1747.

Palma, S.; Lo Nostro, P.; Manzo, R. \& Allemandi, D. (2002). Evaluation of the surfactant properties of ascorbyl palmitate sodium salt. European Journal of Pharmaceutical Sciences, Vol. 16, pp. 37-43.

Pandey, J.D.; Chandra, P.; Srivastava, T.; Soni, N.K. \& Singh, A.K. (2008). Estimation of surface tension of ternary liquid systems by corresponding-states groupcontributions method and Flory theory. Fluid Phase Equilibria, Vol. 273, pp. 44-51.

Podczek, F.; Newton, J.M. \& James, M.B. (1996). The influence of physical properties of the materials in contact on the adhesion strength of particles of salmeterol base and salmeterol salts to various substrate materials. Journal of Adhesion Science and Technology, Vol. 10, pp. 257-268.

Puri, V.; Dantuluri, A.K.; Kumar, M.; Karar, N. \& Bansal, A.K. (2010). Wettability and surface chemistry of crystalline and amorphous forms of a poorly water soluble drug. European Journal of Pharmaceutical Sciences, Vol. 40 pp. 84-93.

Rafati, A.A. \& Ghasemian, E. (2008). Study of surface tension and surface properties of binary alcohol/n-alkyl acetate mixtures. Journal of Colloid and Interface Science, Vol. 328, pp. 385-390.

Ramírez-Flores, J.C.; Bachmann, J. \& Marmur, A. (2010). Direct determination of contact angles of model soils in comparison with wettability characterization by capillary rise. Journal of Hydrology, Vol. 382, pp. 10-19.

Ramírez-Verduzco, L.F.; Romero-Martínez, A. \& Trejo, A. (2006). Prediction of the surface tension, surface concentration, and the relative Gibbs adsorption isotherm of binary liquid systems. Fluid Phase Equilibria, Vol. 246, pp. 119-130. 
Rangsansarid, J. \& Fukada, K. (2007). Factors affecting the stability of O/W emulsion in BSA solution: Stabilization by electrically neutral protein at high ionic strength. Journal of Colloid and Interface Science, Vol. 316, pp. 779-786.

Realdon, N.; Zennaro, L.; Perin, F.; Bettero, A.; Bortoluzzi, S.; Rigo, A. \& Ragazzi, E. (2003). Surface characterisation of bags for total parenteral nutrition by tensiometry and atomic force microscopy. International Journal of Pharmaceutics, Vol. 265, pp. 27-35.

Redlich, O. \& Kister, A.T. (1948). Algebraic representation of thermodynamic properties and the classification of solutions. Industrial and Chemistry Engineering Research, Vol. 40, pp. 341-348.

Santos, N.C. \& Castanho, M.A.R.B. (2004). An overview of the biophysical applications of atomic force microscopy. Biophysical Chemistry, Vol. 107, pp. 133-149.

Schoolenberg, G.E.; During, F. \& Ingenbleek, G. (1998). Coalescence and interfacial tension measurements for polymer melts: experiments on a PS-PE model system. Polymer, Vol. 39, pp. 765-772.

Seifert, A.M. \& Wendorff, J.H. (1992). Spinning drop experiments on interfacial phenomena: Theoretical background and experimental evidence. Colloid Polymer Science, Vol. 270, pp. 962-971.

Semmler, A. \& Kohler, H.-H. (1999). Surface properties of Alkylpyridinium Chlorides and the applicability of the pendant drop technique. Journal of Colloid and Interface Science, Vol. 218, pp. 137-144.

Shereshefsky, J.L. (1967). A theory of surface tension of binary solutions. 1. Binary liquid mixtures of organic compounds. Journal of Colloid and Interface Science, Vol. 24, pp. 317-322.

Sipahi, C.; Anil, N. \& Bayramli, E. (2001). The effect of acquired salivary pellicle on the surface free energy and wettability of different denture base materials. Journal of Dentistry, Vol. 29, pp. 197-204.

Stückrad, B.; Hiller, W.J. \& Kowalewski, T.A. (1993). Measurement of dynamic surface tension by the oscillating droplet method. Experiments in Fluids, Vol. 15, pp. 332-340.

Sugden S., (1924). The influence of the orientation of surface molecules on the surface tension of pure liquids. Journal of Chemical Society Transaction, Vol. 125, pp. 11671177.

Tahery, R.; Modarress, H. \& Satherley, J. (2005). Surface tension prediction and thermodynamic analysis of the surface for binary solutions. Chemical Engineering Science, Vol. 60, pp. $4935-4952$.

Takamura, A.; Ishii, F.; Noro, S.; Tanifuji, M. \& Nakajima, S. (1984). Study of intravenous hyperalimentation: effect of selected amino acids on the stability of intravenous fat emulsions. Journal of Pharmaceutical Science, Vol. 73, pp. 91-94.

Tan, S.N.; Fornasiero, D.; Sedev, R. \& Ralston, J. (2005). Marangoni effects in aqueous polypropylene glycol foams. Journal of Colloid and Interface Science, Vol. 286, pp. 719729.

Taskinen, J. \& Yliruusi, J. (2003). Prediction of physicochemical properties based on neural network modeling. Advanced Drug Delivery Reviews, Vol. 55, pp. 1163-1183.

Thiessen, D.B. \& Man, K.F. (1999). Surface tension measurements, CRC Press, Retrieved from <http:/ / www.engnetbase.com> 
Thomas, W.D.E. \& Potter, L. (1975). Solution/Air Interfaces I. An oscillating jet relative method for determining dynamic surface tensions. Journal of Colloid and Interface Science. Vol. 50. pp. 397-412.

Trukhin, D.V.; Sinyachenko, O.V.; Kazakov, V.N.; Lylyk, S.V.; Belokon, A.M. \& Pison, U. (2001). Dynamic surface tension and surface rheology of biological liquids. Colloids and Surfaces B: Biointerfaces, Vol. 21, pp. 231-238.

van Oss, C.J.; Good, R.J. \& Chaudhury, M.K. (1986). The role of van der Waals forces and hydrogen bonds in "hydrophobic interactions" between biopolymers and low energy surfaces. Journal of Colloid and Interface Science, Vol. 111, pp. 378-390.

Vasir, J.K.; Tambwekar, K. \& Garg, S. (2003). Bioadhesive microspheres as a controlled drug delivery system. International Journal of Pharmaceutics, Vol. 255, pp. 13-32.

Vejnovic, I.; Simmler, L. \& Betz, G. (2010). Investigation of different formulations for drug delivery through the nail plate, International Journal of Pharmaceutics, Vol. 386, pp. 185-194.

Warszunski, P.; Wantke, K.-D. \& Fruhner, H. (1998). Surface elasticity of oscillating spherical interfaces, Colloids and Surfaces A, Vol. 139, pp. 137-153.

Xue, H.T.; Fang, Z.N.; Yang, Y.; Huang, J.P. \& Zhou, L.W. (2006). Contact angle determined by spontaneous dynamic capillary rises with hydrostatic effects: Experiment and theory. Chemical Physics Letters, Vol. 432, pp. 326-330.

Zelkó, R.; Orbán, Á.; Süvegh, K.; Riedl, Z. \& Rácz, I. (2002). Effect of plasticizer on the dynamic surface tension and the free volume of Eudragit systems. International Journal of Pharmaceutics, Vol. 244, pp. 81-86.

Zhang, L.-H. \& Zhao, G.-X. (1989). Dynamic surface tension of the aqueous solutions of cationic-anionic surfactant mixtures. Journal of Colloid and Interface Science, Vol. 127, pp. 353-361.

Zhou, G.; Ge, W. \& Li, J. (2008). A revised surface tension model for macro-scale particle methods. Powder Technology, Vol. 183, pp. 21-26. 


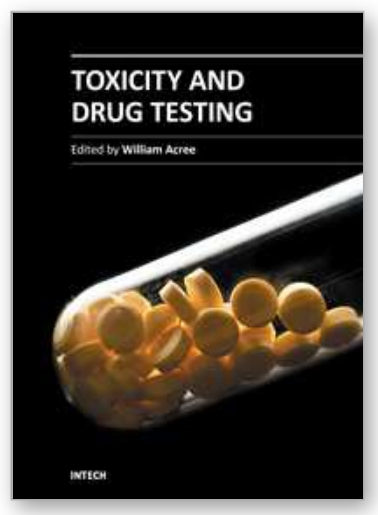

\author{
Toxicity and Drug Testing \\ Edited by Prof. Bill Acree
}

ISBN 978-953-51-0004-1

Hard cover, 528 pages

Publisher InTech

Published online 10, February, 2012

Published in print edition February, 2012

Modern drug design and testing involves experimental in vivo and in vitro measurement of the drug candidate's ADMET (adsorption, distribution, metabolism, elimination and toxicity) properties in the early stages of drug discovery. Only a small percentage of the proposed drug candidates receive government approval and reach the market place. Unfavorable pharmacokinetic properties, poor bioavailability and efficacy, low solubility, adverse side effects and toxicity concerns account for many of the drug failures encountered in the pharmaceutical industry. Authors from several countries have contributed chapters detailing regulatory policies, pharmaceutical concerns and clinical practices in their respective countries with the expectation that the open exchange of scientific results and ideas presented in this book will lead to improved pharmaceutical products.

\title{
How to reference
}

In order to correctly reference this scholarly work, feel free to copy and paste the following:

Abolghasem Jouyban and Anahita Fathi-Azarbayjan (2012). Experimental and Computational Methods Pertaining to Surface Tension of Pharmaceuticals, Toxicity and Drug Testing, Prof. Bill Acree (Ed.), ISBN: 978953-51-0004-1, InTech, Available from: http://www.intechopen.com/books/toxicity-and-drugtesting/experimental-and-computational-methods-pertaining-to-surface-tension-of-pharmaceuticals

\section{INTECH}

open science | open minds

\author{
InTech Europe \\ University Campus STeP Ri \\ Slavka Krautzeka 83/A \\ 51000 Rijeka, Croatia \\ Phone: +385 (51) 770447 \\ Fax: +385 (51) 686166 \\ www.intechopen.com
}

\author{
InTech China \\ Unit 405, Office Block, Hotel Equatorial Shanghai \\ No.65, Yan An Road (West), Shanghai, 200040, China \\ 中国上海市延安西路65号上海国际贵都大饭店办公楼 405 单元 \\ Phone: +86-21-62489820 \\ Fax: +86-21-62489821
}


(C) 2012 The Author(s). Licensee IntechOpen. This is an open access article distributed under the terms of the Creative Commons Attribution 3.0 License, which permits unrestricted use, distribution, and reproduction in any medium, provided the original work is properly cited. 